\title{
Álcool e Câncer Bucal: Considerações sobre os Mecanismos Relacionados
}

\author{
Alcohol and Oral Cancer: Comments on Related Mechanisms
}

\author{
Vinícius Coelho Carrard', Aline Segatto Pires², Ricardo Losekann Paiva', Anna Cecília Moraes Chaves', Manoel Sant'Ana Filho'
}

\section{Resumo}

O consumo de álcool é um dos fatores de risco para o desenvolvimento do câncer bucal; entretanto, os mecanismos envolvidos no dano gerado pelo álcool são parcialmente compreendidos. Determinadas concentraçóes de álcool causam aumento da permeabilidade da mucosa bucal, potencializando a penetração de carcinógenos. Além disso, é responsável por um aumento na proliferação epitelial, bem como pela modificação do seu processo de maturação. Outras alterações, como redução da capacidade de reparo de DNA, distúrbios do sistema imune e do estado nutricional podem contribuir na sua relação com o desenvolvimento do câncer bucal. O metabolismo do álcool aumenta a produção de radicais livres e diminui os mecanismos antioxidantes, levando ao estresse oxidativo. $\mathrm{O}$ polimorfismo genético das enzimas de degradação do álcool pode ser responsável pela diferença na sensibilidade individual. Algumas isoformas dessas enzimas permitem o acúmulo de metabólitos tóxicos como o acetadeído, que pode causar dano ao DNA ou a outras estruturas celulares. A partir de uma revisão de literatura, esse trabalho tem como objetivo estabelecer uma relação entre os diferentes mecanismos da ação do álcool e a carcinogênese na cavidade oral.

Palavras-chave: Etanol, Carcinoma de células escamosas, Mucosa bucal

${ }^{1}$ Programa de Pós-graduação em Patologia Bucal da Faculdade de Odontologia da Universidade Federal do Rio Grande do Sul (UFRGS) - Porto Alegre (RS), Brasil

${ }^{2}$ Curso de Graduação da Faculdade de Odontologia da Universidade Federal do Rio Grande do Sul (UFRGS) - Porto Alegre (RS), Brasil

Endereço para correspondência: Vinicius Coelho Carrard. Rua Ramiro Barcelos, 2492 - apto. 503 - Porto Alegre (RS), Brasil - CEP: $90035-003$.

E-mail: vcarrard@yahoo.com.br 


\section{INTRODUÇÃO}

O consumo de álcool é um dos principais fatores de risco relacionados ao desenvolvimento do câncer de boca. O dano provocado pelo consumo de álcool na mucosa oral pode ser resultado de sua ação direta, pela sua presença na corrente sangüínea ou de sua atuação sobre outros sistemas. Diversos mecanismos podem influenciar a mucosa oral, não estando claro na literatura qual desses seria o mais importante no que diz respeito à carcinogênese em boca. A partir de uma revisão de literatura, este trabalho tem como objetivo estabelecer uma relação entre os diferentes mecanismos da ação do álcool e a carcinogênese na cavidade oral.

Os artigos foram localizados através de busca na base de dados Medline, fazendo o cruzamento das palavras "oral mucosa" e "alcohol". Dentre os trabalhos encontrados, foram selecionados aqueles que se enquadravam no enfoque do trabalho e mais relevantes em termos de delineamento e resultados encontrados. Alguns artigos citados nesses trabalhos foram utilizados, a fim de trazer informaçôes complementares.

\section{REVISÃO DE LITERATURA}

O consumo de álcool (etanol) tem aumentado em várias populações, e a faixa etária dos indivíduos consumidores tem sido cada vez mais baixa ${ }^{1,2}$. Diversos estudos epidemiológicos têm mostrado que o consumo de álcool é um fator de risco para o desenvolvimento de carcinoma espinocelular, que é o tipo de câncer mais comum na cavidade oral ${ }^{3-9}$.

Esta relação é ainda mais evidente quando há associação com o hábito de fumar, o que se observa na maioria dos indivíduos, dificultando o estudo de sua ação isolada ${ }^{6,9-14}$.

O estudo dos efeitos do consumo de álcool na cavidade oral encontra uma série de dificuldades, pois os indivíduos geralmente ingerem diferentes graduaçōes alcoólicas e são imprecisos ao informar a respeito das doses ingeridas, quando questionados ${ }^{3,15,16}$.

Segundo Mashberg et al. ${ }^{11}$, bebidas como cerveja e vinho aumentariam mais o risco de câncer bucal do que whisky. Contudo, a quantidade total de álcool ingerida $^{17,18}$ e o tempo de duração do hábito ${ }^{19}$ são mais importantes do que o tipo de bebida alcoólica ingerida.

Mesmo que estudos demonstrem alguns mecanismos por meio dos quais o álcool provoca alteraçōes, não existe ainda uma completa compreensão de como eles podem modificar a mucosa bucal no sentido de desenvolver um carcinoma espinocelular ${ }^{20,21}$.

Estudos in vitro mostram que, a partir da aplicação tópica, o álcool modifica a permeabilidade da mucosa bucal. Isto parece uma boa explicação para o sinergismo entre consumo de álcool e fumo no desenvolvimento de câncer de boca, uma vez que o consumo de bebidas com concentração alcoólica entre 15\% e 25\% facilitaria a penetração de diferentes substâncias, inclusive as carcinogênicas presentes no fumo ${ }^{22-24}$. Por um mecanismo ainda desconhecido, o álcool impede que as células epiteliais organizem a barreira de permeabilidade, composta principalmente de lipídios que têm a função de impedir a desidratação e a penetração de agentes externos ${ }^{25,26}$. Além disso, é provável que a ação do fumo e álcool sobre os outros sistemas tenha uma contribuição considerável.

A mucosa bucal não é local preferencial para a degradação do álcool, mas alguma quantidade é absorvida e metabolizada em nível tecidual durante a deglutição. Através da principal rota de degradação, o álcool é convertido pela enzima álcool-desidrogenase $(\mathrm{ADH}) \mathrm{em}$ acetaldeído, e este em acetato pela enzima aldeídodesidrogenase (ALDH). Posteriormente, o acetato chega até diferentes partes do organismo, onde pode ser utilizado para produzir energia ou outras moléculas úteis pela rota de degradação comum à da glicose. Entretanto, a atividade da ALDH é baixa na boca, podendo haver acúmulo de acetaldeído no epitélio bucal ${ }^{27,28}$.

Usualmente, o acetaldeído é rapidamente convertido em acetato, mas em determinadas situaçōes pode haver o seu acúmulo: o consumo contínuo ou de altas doses de álcool, bem como degradação parcial pela presença de enzimas (ALDH) com atividade limitada. Segundo Bird et al. ${ }^{29}$ e Dellarco ${ }^{30}$, o acetaldeído é um metabólito tóxico capaz de provocar a quebra da dupla fita de DNA e de formar complexos (adducts) com diferentes moléculas, principalmente com proteínas, o que compromete o metabolismo celular.

Há diferentes isoformas de ADH e ALDH, codificadas por diferentes genes, o que determina uma variabilidade étnica e individual na capacidade de degradação do álcool, ocorrendo, em alguns indivíduos, o acúmulo de acetaldeído a partir da ingestão de quantidades relativamente pequenas de álcool ${ }^{28,31}$. Harty et al. ${ }^{32}$ demonstraram que os indivíduos portadores da $\mathrm{ADH} 3$ (alelo da rápida metabolização do álcool) apresentam um risco aumentado de desenvolvimento de câncer de boca, quando comparados com os indivíduos portadores da $\mathrm{ADH} 1$. Entre as ALDH encontram-se as isoenzimas ALDH1 e ALDH2. A ALDH2 é predominante na população japonesa e chinesa, possuindo uma menor capacidade de oxidação do acetaldeído. Portanto, essas populações estariam mais suscetíveis aos danos provocados pelo consumo de álcool, uma vez que acumulam acetaldeído mais facilmente ${ }^{27,33}$. Segundo Yokohama et al. ${ }^{34}$ e Väkeväinen et al. ${ }^{35}$, indivíduos portadores da ALDH2 inativa têm um maior risco para o desenvolvimento de câncer de boca. Existe, ainda, 
uma diferença no metabolismo relacionada ao sexo, pois nas mulheres a $\mathrm{ADH}$ é menos ativa ${ }^{36}$. Esses estudos são controversos, mas é provável que o polimorfismo das enzimas que degradam o etanol tenha uma contribuição na suscetibilidade individual ao desenvolvimento do câncer bucal.

Após a demonstração de que a microbiota bucal teria a capacidade de metabolizar álcool em acetaldeído, surgiram novas especulações quanto a possíveis mecanismos envolvidos no dano pelo consumo de etanol ${ }^{37,38}$. A má higiene bucal promoveria uma maior produção de acetaldeído, pois permite um maior acúmulo microbiano ${ }^{39}$. Estudos demonstraram a Cândida albicans ${ }^{39}$ e a Neisseria ${ }^{40}$ como espécies que se destacam na produção de acetaldeído por possuírem alta atividade de $\mathrm{ADH}$, estando mais presentes na microbiota bucal de indivíduos alcoolistas. Uma vez que o acetaldeído é produzido a partir de microrganismos bucais em indivíduos com higiene bucal deficiente ${ }^{38}$, pode-se explicar a relação entre status bucal e risco de desenvolvimento de câncer de boca ${ }^{41,42}$.

Alguns estudos analisaram a influência do consumo de álcool na morfologia e no processo de renovação celular do epitélio bucal. A maioria deles concorda que o consumo crônico de álcool provoca uma diminuição da sua espessura ${ }^{43-46}$. Ogden et al. ${ }^{21}$ e Larentis et al. ${ }^{47}$ concordam que essa redução de espessura seria o resultado do aumento da descamação celular, apesar de alguns autores terem mostrado que ela poderia decorrer da redução do volume das células ${ }^{45,48,49}$.

Maier et al. ${ }^{43}$, Homman et al. ${ }^{37}$, Maito et al. ${ }^{50} \mathrm{e}$ Carrard et al. ${ }^{51}$ mostraram um aumento da proliferação celular decorrente do consumo crônico de álcool, enquanto Mascres et al. ${ }^{44}$, Martinez et al..$^{49}$, Martinez et al. ${ }^{48}$ e Slomiany et al. ${ }^{52}$ relacionaram-no com um aumento da autólise ou morte celular. Embora esses resultados pareçam inicialmente contraditórios, nada impede que o aumento da proliferação celular nas camadas mais profundas do tecido epitelial seja uma resposta adaptativa ao aumento da morte celular nas camadas mais externas, a fim de que seja mantida a homeostase ${ }^{51}$. Conclui-se dessa forma que o aumento da proliferação celular estaria atuando de maneira compensatória para manter a integridade do tecido epitelial, e poderia favorecer uma maior ocorrência de mutações e danos cumulativos, levando ao desenvolvimento do câncer.

O processo de maturação epitelial parece também ser influenciado pela ingestão de álcool. Isso fica evidente através da observação de vesículas lipídicas ${ }^{44,48,49}$ e da maior expressão de citoqueratina $14^{37}$ nas células epiteliais das mucosas de animais que consomem álcool e conseqüentemente denota uma alteração do metabolismo lipídico, o que pode influenciar a organização da barreira de permeabilidade que, normalmente, impede a penetração de antígenos e substâncias do meio externo.

Experimentos, nos quais o acetaldeído foi administrado a animais ${ }^{37}$, mostraram alterações semelhantes às encontradas na mucosa bucal após o consumo de álcool ${ }^{37,43,50,51}$, indicando que o acetaldeído pode ser o principal responsável pelo dano gerado pelo álcool $^{53}$.

Vários autores sugerem que o álcool tem efeito no mecanismo de reparo de DNA. Alguns experimentos têm demonstrado que o consumo crônico de álcool diminui a capacidade de promover reparos do DNA frente a mutaçōes ${ }^{54-57}$.

A partir da análise dos diferentes estudos realizados, depreende-se que os efeitos do consumo de álcool ocorrem devido a uma sobreposição de fatores locais e sistêmicos ${ }^{20}$.

O principal órgão de degradação do álcool é o fígado, onde, além da $\mathrm{ADH}$, existem mais duas rotas de metabolização: sistema microssomal de degradação do etanol (MEOS) e a rota da catalase ${ }^{58}$. O MEOS envolve o retículo endoplasmático liso, encontrando-se mais desenvolvido nos hepatócitos de alcoolistas. As enzimas microssomais pertencem à família de proteínas chamadas citocromos, sendo que a responsável pela oxidação do etanol chama-se P450 2E1 ou CYP 2E $1^{59}$. Como muitos pró-carcinógenos são ativados por essa rota enzimática, poderia se esperar uma maior ativação de carcinógenos frente à ingestão contínua de álcool ${ }^{60,61}$. A rota da catalase é pouco conhecida e, em termos quantitativos, tem pouca participação na degradação do etanol.

O fígado é um dos principais prejudicados pelo consumo de álcool, que provoca determinados tipos de esteatoses, cirroses e hepatites ${ }^{28}$. Estando o fígado incapacitado de depurar toxinas, estas se manteriam no sangue e poderiam afetar outros tecidos a distância, por exemplo, a mucosa bucal ${ }^{62}$. Também não pode ser descartada a hipótese das alterações hepáticas serem responsáveis pela má estruturação da barreira de permeabilidade da mucosa bucal, uma vez que no fígado ocorre o metabolismo dos lipídios. Existe ainda a possibilidade de uma menor disponibilização de vitaminas, pois essas são processadas no fígado ${ }^{63,64}$.

O sistema imunológico também é afetado pelo uso do álcool ${ }^{65}$. Segundo Lundy et al..$^{66}$, Gallucci et al. ${ }^{67} \mathrm{e}$ Wang et al. ${ }^{68}$, há uma diminuição do número e da função das células de defesa do sangue, como as células $\mathrm{T}$ e as "natural killer". Isso explica o pobre prognóstico observado em pacientes portadores de câncer de cabeça e pescoço que consomem habitualmente álcool. Por outro lado, aqueles indivíduos que se abstiveram do consumo, por pelo menos um ano, antes do estabelecimento do diagnóstico de câncer, apresentaram uma sobrevida maior $^{69}$. Percebe-se, portanto, que, além de contribuir 
no surgimento do câncer, o consumo de etanol parece ter um papel na evolução da doença.

Somando-se a isto, o alto valor calórico do álcool faz com que o alcoolista se alimente mal, potencializando ainda mais esse estado de imunossupressão ${ }^{70,71}$. Adicionalmente, o contato do álcool com a mucosa do trato intestinal resulta em alteraçôes na sua morfologia e no processo de renovação celular, diminuindo a absorção de nutrientes ${ }^{71-75}$. Esse problema absortivo gera ainda mais repercussōes, pois micronutrientes como, por exemplo, a vitamina $\mathrm{A}$ (retinóides), são importantes para o controle da diferenciação em diferentes tecidos epiteliais.

O consumo de álcool afeta o metabolismo da vitamina $\mathrm{A}$ em diferentes aspectos, incluindo sua absorção, degradação e distribuiçãa ${ }^{76}$, reduzindo seus níveis sangüíneos ${ }^{77}$. Nas células epiteliais, álcool e vitamina A competem pelo mesmo receptor. Assim, na presença do álcool, a absorção de vitamina A pela célula e subseqüente conversão em ácido retinóico, que é necessário para a diferenciação celular, vai se dar de forma inapropriada, o que explica a alteração da maturação epitelial encontrada na mucosa bucal de animais submetidos à ingestão de álcool ${ }^{43,44-46,78}$.

O consumo crônico de álcool mostra relação com redução dos níveis de retinóides na cavidade bucal ${ }^{79}$. Em experimentos com animais, a relação entre deficiência de vitamina A e câncer tem sido encontrada, assim como um aumento da suscetibilidade a carcinógenos químicos ${ }^{80}$. Por outro lado, Mak et al. ${ }^{81}$, estudando a influência da ingestão do álcool e da deficiência de vitamina A na proliferação e na estrutura da mucosa do esôfago de ratos, mostraram que seus efeitos são independentes. A deficiência de vitamina A, independentemente da ação do álcool, produziu diminuição do número de células na camada basal e aumento dos grânulos de cerato-hialina, denotando alteração no padrão de maturação celular. Nos animais que receberam álcool, houve um aumento da proliferação celular no epitélio da mucosa esofágica, na presença ou ausência da vitamina A. A partir desses resultados, concluíram que o álcool ou seus metabólitos exercem efeito direto na proliferação celular do esôfago, e que o álcool seria um fator de risco para o câncer, enquanto que a deficiência de vitamina A provocaria apenas distúrbios de maturação epitelial.

Rennie et al. ${ }^{82}$ e Scott et al. ${ }^{83}$ mostraram que, isoladamente, a má nutrição é capaz de provocar atrofia da mucosa bucal, tornando o indivíduo mais suscetível à ação de agentes externos, como antígenos, carcinógenos e produtos bacterianos. Mais uma vez observa-se a superposição dos efeitos diretos e indiretos do consumo de etanol sobre a mucosa, reforçando a característica multifatorial dessa relação.

O metabolismo do álcool produz elementos instáveis chamados radicais livres (RL), principalmente quando a P450 2E1 é utilizada como rota de degradação ${ }^{28,84-86}$. $\mathrm{O}$ organismo tem mecanismos de defesa para neutralizar esses RL gerados, conhecidos como mecanismos antioxidantes enzimáticos e não-enzimáticos. RL que não são neutralizados pelos mecanismos antioxidantes podem reagir com proteínas, lipídios ou mesmo com o DNA, formando complexos e danificando-o ${ }^{55,86,87}$. Como estas ligações são estáveis, diferentes funções celulares podem ser perturbadas como, por exemplo, o transporte intracelular e a síntese proteica.

Adicionalmente, o consumo de álcool modifica a capacidade antioxidante do organismo, reduzindo tanto a atividade dos mecanismos enzimáticos como a dos não-enzimáticos, levando ao estado de desequilíbrio chamado estresse oxidativo.

As vitaminas $\mathrm{A}, \mathrm{C}$ e $\mathrm{E}$, que fazem parte dos mecanismos não-enzimáticos, têm seus níveis reduzidos pela baixa ingesta, má absorção e disponibilização deficiente a partir do fígado ${ }^{88}$. Outros trabalhos utilizaram administração intragástrica de álcool em ratos e camundongos, encontrando diminuição da atividade de uma das principais enzimas antioxidantes (SODsuperóxido-dismutase) nas células hepáticas ${ }^{89}$.

Alguns estudos têm mostrado uma forte relação entre estresse oxidativo e danos causados pelo álcool. Alguns autores mostram que, frente ao aumento da capacidade antioxidante do organismo, observa-se uma atenuação ou reversão dos danos provocados pelo consumo de álcool. Zhou et al.$^{90}$ verificaram que em camundongos, nos quais se induziu uma superexpressão de metalotioneína, um potente antioxidante, houve uma prevenção nos danos hepáticos observados frente ao consumo de álcool. Vincon et al..${ }^{91}$ demonstraram que o aumento de proliferação celular observado no epitélio intestinal de camundongos que consumiam álcool foi revertido quando lhes era administrada vitamina E. Esses achados não só sugerem que o aumento da proliferação celular pode ser uma resposta à presença de RL não neutralizados, mas também que o dano provocado pode ser reversível.

Outros estudos submeteram animais à ação de carcinógenos na presença e ausência de vitamina E, sendo que a ocorrência de carcinomas espinocelulares e de displasias epiteliais na mucosa bucal foi menor quando da exposição concomitante à vitamina $\mathrm{E}^{92}$. Esses achados abrem uma nova perspectiva, indicando que o estresse oxidativo pode ser o principal mecanismo envolvido no dano gerado pelo consumo de álcool. Entretanto, como ainda não foram realizados estudos em que essa hipótese pudesse ser testada na mucosa bucal, esta consideração permanece como uma especulação.

O consumo de álcool poderia ainda afetar a mucosa bucal indiretamente pela alteração das glândulas salivares. A morfologia e a função dessas estruturas 
encontram-se alteradas em decorrência da ingestão crônica de álcool, o que inclui aumento de volume das glândulas em função de uma fibrose e infiltração gordurosa ${ }^{83,93-95}$, bem como diminuição do fluxo salivar ${ }^{95,96}$. Segundo Wu-Wang et al. ${ }^{97}$, isso se deve ao fato de o álcool provocar uma diminuição das prostaglandinas PG2, PGF2 e 6-keto-PGF1, que normalmente atuam estimulando o fluxo salivar.

Essa redução poderia potencializar o estresse oxidativo, já que a saliva apresenta imunoglobulinas, fatores de crescimento e antioxidantes que são importantes na proteção e na manutenção da homeostase da mucosa bucal ${ }^{98-99}$. Além disso, com a redução do fluxo salivar, haveria um prejuízo na ação de "lavagem" das superfícies das mucosas, deixandoas mais expostas à ação de carcinógenos que, eventualmente, estariam presentes na boca. Ademais, ao utilizar a água proveniente do sangue na produção de saliva, poderia haver a redistribuição do álcool ou o acetaldeído para a cavidade bucal, aumentando ainda mais os seus efeitos já discutidos anteriormente. $\mathrm{O}$ fato de o aumento da proliferação epitelial das mucosas desaparecer frente à remoção das glândulas salivares reforça essa hipótese ${ }^{95}$.

\section{CONCLUSÕES}

Apesar de o consumo de álcool poder influenciar a mucosa bucal por meio de diferentes mecanismos, ainda não está claro na literatura até que ponto o álcool isoladamente pode ser responsável pelo desenvolvimento de câncer de boca. Mesmo que uma possível explicação para o aumento de risco de desenvolvimento de carcinomas espinocelulares de boca em indivíduos expostos ao álcool e ao tabaco seja dada pelos estudos de permeabilidade, ainda há dúvidas sobre o quanto cada um dos possíveis mecanismos envolvidos pode contribuir. Esse tema é bastante complexo, pois esses mecanismos se inter-relacionam, sendo difícil estabelecer o real impacto de cada um deles. Há necessidade de mais estudos para esclarecer esses mecanismos, especialmente em relação ao polimorfismo genético das enzimas de degradação e ao papel do estresse oxidativo no mecanismo de dano relacionado ao álcool.

Potencial Conflito de Interesses:

Declaro não haver conflitos de interesses pertinentes.

\section{AGRADECIMENTOS}

Os autores gostariam de agradecer o apoio prestado pela Bibliotecária Malvina Vianna Rosa, da Faculdade de Odontologia, na busca dos artigos científicos e pela acadêmica Marina Mendez.

\section{REFERÊNCIAS}

1. Almeida-Filho N, Lessa I, Magalhaes L, Araújo MJ, Aquino E, James SA, et al. Alcohol drinking patterns by gender, ethnicity, and social class in Bahia, Brazil. Rev Saúde Pública. 2004;38(1):45-54.

2. Ferigolo M, Barbosa FS, Arbo E, Malysz AS, Stein AT, Barros HM. Drug use prevalence at FEBEM, Porto Alegre. Rev Bras Psiquiatr. 2004;26(1):10-16.

3. Wynder EL, Bross IJ, Feldman RM. A study of the etiological factors in cancer of the mouth. Cancer. 1957;10(6):1300-323.

4. La Vecchia C, De Carli A, Mezzanotte G, Cislaghi C. Mortality from alcohol related disease in Italy. J Epidemiol Community Health. 1986;40(3):257-61.

5. LeclercA, BrugereJ, LuceD, Point D, Guenel P.Type of alcoholic beverage and cancer of the upper respiratory and digestive tract. Eur J Cancer Clin Oncol. 1987;23(5):529-34.

6. Franco EL, Kowalski LP, Oliveira BV, Curado MP, Pereira $\mathrm{RN}$, Silva ME, et al. Risk factors for oral cancer in Brazil: A case-control study. Int J Cancer. 1989;43(6):992-1000.

7. Fioretti F, Bosetti C, Tavani A, Franceschi S, La Vecchia C. Risk factor for oral pharyngeal cancer in never smokers. Oral Oncol. 1999;35(4):375-78.

8. De Stefani E, Boffetta P, Oreggia F, Fierro L, Mendilaharsu M. Hard liquor drinking is associated with higher risk of cancer of the oral cavity and pharynx than wine drinking. A case-control study in Uruguay. Oral Oncol. 1998;34(2):99-104.

9. Llewellyn CD, Johnson NW, Warnakulasuriya KA. Risk factors for oral cancer in newly diagnosed patients aged 45 years and younger: a case-control study in Southern England. J Oral Pathol Med. 2004;33(9):525-32.

10. Wynder EL, Mushinski MH, Spivak JC. Tobacco and alcohol consumption in relation to the development of multiple primary cancers. Cancer. 1977;40(4 suppl):1872-878.

11. Mashberg A, Garfinkel L, Harris S. Alcohol as a primary risk factor in oral squamous carcinoma. CA Cancer J Clin. 1981;31(3):146-55.

12. Rothman KJ. Epidemiology of head and neck cancer. Laryngoscope. 1978;88(3):435-38.

13. Rich AM, Radden BG. Squamous cell carcinoma of the oral mucosa: a review of 244 cases in Australia. J Oral Pathol. 1984;13(5):459-71.

14. Franceschi S, Talamini R, Barra S, Baron AE, Negri E, Bidoli $\mathrm{E}$, et al. Smoking and drinking in relation to cancers of the oral cavity, pharynx, larynx, and esophagus in Northern Italy. Cancer Res. 1990;50(20):6502-507.

15. Brugere J, Guenel P, Leclerc A, Rodriguez J. Differential effects of tobacco and alcohol in cancer of the larynx, pharynx and mouth. Cancer. 1986;57(2):391-95.

16. Kabat GC, Wynder EL. Type of alcoholic beverage and oral cancer. Int J Cancer. 1989;43(2):190-94. 
17. Keller AZ, Terris M. The association of alcohol and tobacco with cancer of the mouth and pharynx. Am J Public Health. 1965;55(10):1578-585.

18. Kato I, Nomura AM. Alcohol in the etiology of upper aerodigestive tract cancer. Eur J Cancer B Oral Oncol. $1994 ; 30 \mathrm{~B}(2): 75-81$.

19. Kissin B, Kaley MM, Su WH, Lerner R. Head and neck cancer in alcoholics. The relationship to drinking, smoking and dietary patterns. JAMA. 1973;224(8):1174-175.

20. Ogden GR, Wight AJ. Aetiology of oral cancer: alcohol. Br J Oral Maxillofac Surg. 1998;36(4):247-51.

21. Ogden GR, Wight AJ, Rice P. Effect of alcohol on the oral mucosa assessed by quantitative cytimorphometry. J Oral Pathol Med. 1999;28(5):216-20.

22. Squier CA, Cox P, Hall BK. Enhanced penetration of nitrosonornicotine across oral mucosa in the presence of ethanol. J Oral Pathol. 1986;15(5):276-79.

23. Du X, Squier CA, Kremer MJ, Wertz PW. Penetration of $\mathrm{N}$-nitrosonomicotine (NNN) across oral mucosa in the presence of ethanol and nicotine. J Oral Pathol Med. 2000;29(2):80-85.

24. Howie NM, Trigkas TK, Cruchley AT, Wertz PW, Squier CA, Williams DM. Short-term exposure to alcohol increases the permeability of human oral mucosa. Oral Dis. 2001;7(6):349-54.

25. Squier CA, Wertz PW. Structure and function of the oral mucosa and implications for drug delivery. In: Rathbone MJ (ed). Oral mucosa drug delivery. New York: Marcel Dekker; 1996:1-26.

26. Squier CA, Finkelstein MW. Mucosa bucal. In: Ten Cate AR. Histologia bucal: desenvolvimento, estrutura e função. 5a ed. Rio de Janeiro: Guanabara Koogan; 2001:323-39.

27. Dong YJ, Peng TK, Yin SJ. Expression and activities of class IV alcohol dehydrogenase and class III alcohol dehydrogenase in human mouth. Alcohol. 1996;13(3)257-62.

28. Maher JJ. Exploring alcohol's effects on liver function. Alcohol Health Res World. 1997;21(1):5-12.

29. Bird RP, Draper HH, Badsur PK. Effect of malonaldehyde and acetaldehyde on cultured mammalian cells. Production of micronuclei and cromossomal aberrations. Mutat Res. 1982;101(3):237-46.

30. Dellarco VL. A mutagenicity assessment of acetaldehyde. Mutat Res. 1988;195(1):1-20.

31. Ramchandani VA, Bosron WF, LiTK. Research advances in ethanol metabolism. Pathol Biol. 2001;49(9):676-82.

32. Harty LC, Corporaso NE, Hayes RB, Winn DM, BravoOtero E, Blot WJ, et al. Alcohol dehydrogenase-3 genotype and risk of oral cavity and pharyngeal cancers. J Natl Cancer Inst. 1997;89(22):1698-705.

33. Yin SJ, Chou FJ, Chao SF, Tsai SF, Liao CS, Wang CW, et al. Alcohol and aldehyde dehydrogenases in human esophagus. Comparison with the stomach enzyme activity. Alcohol
Clin Exp Res. 1993;17(2):376-82.

34. Yokohama A, Muramatsu T, Ohmori T, Higuchi S, Hayashida M, Ishii H. Esophageal cancer aldehydedehydrogenase-2 genotypes in Japanese males. Cancer Epidemiol Biomarkers Prev. 1996;5(2):99-102.

35. Väkeväinen S, Tillonen J, Agarwal DP, Srivastava N, Salaspuro M. High salivary acetaldehyde after a moderate dose of alcohol in ALDH2-deficient subjects: strong evidence for the local carcinogenic action of acetaldehyde. Alcohol Clin Exp Res. 2000;24(6):873-77.

36. Mumenthaler MS, Taylor JL, O'Hara R, Yesavage JA. Gender differences in moderate drinking effects. Alcohol Res Health. 1999;23(1):55-64.

37. Homann N, Karkkainen P, Koivisto T, Nosova T, Jokelainen K, Salaspuro M. Effects of acetaldehyde on cell regeneration and differentiation of the upper gastrointestinal tract mucosa. J Natl Cancer Inst. 1997;89(22):1692-697.

38. Homann N, Tillonen J, Rintamaki H, Salaspuro M, Lindqvist C. Poor dental status increases acetaldehyde production from ethanol in saliva a possible link to increased oral cancer risk among heavy drinkers. Oral Oncol. 2001;37(2):153-58.

39. Tilonem J, Homann N, Rautio M, Jousimies-Somer H, Salaspuro M. Role of yeasts in the salivary acetaldehyde production from ethanol among risk groups for ethanolassociated oral cavity cancer. Alcohol Clin Exp Res. 1999;23(8):1409-415.

40. Muto M, Hitomi Y, Ohtsu A, Shimada H, Kashiwase Y, Sasaki H, et al. Acetaldehyde production by nonpathogenic Neisseria in human oral microflora: implications for carcinogenesis in upper aerodigestive tract. Int J Cancer. 2000;88(3):342-50.

41. Smith EM. Epidemiology of oral and pharyngeal cancers in the United States: review of recent literature. J Natl Cancer Inst. 1979;63(5):1189-198.

42. Elwood JM, Pearson JC, Skippen DH, Jackson SM. Alcohol, smoking, social and occupational factors in the aetiology of cancer of the oral cavity, pharynx and larynx. Int J Cancer. 1984;34(5):603-12.

43. Maier H, Weidauer H, Zoller J, Seitz HK, Flentje M, Mall $\mathrm{G}$, et al. Effect of chronic alcohol consumption on the morphology of the oral mucosa. Alcohol Clin Exp Res. 1994;18(2):387-97.

44. Mascres C, Joly JG. Histochemical and ultrastructural study of the rat oral mucosa, after chronic administration of alcohol. J Biol Buccale. 1981;9(3):279-95.

45. Valentine JA, Scott J, West CR, St Hill CA. A histological analysis of the early effects of alcohol and tobacco usage on human lingual epithelium. J Oral Pathol. 1985;14(8):654-65.

46. Sanfelice JC, Padilha DMP, Sant'Ana Filho M. Morphological changes in epithelium of the tongue of mice exposed to $40^{\circ} \mathrm{GL}$ alcohol solution. Rev Fac Odontol de Porto Alegre. 2003;44(1):3-14. 
47. Larentis CL, Gedoz L, Maito FDM, Sanfelice J, Sant'Ana Filho M, Rados PV. Avaliação citopatológica da mucosa bucal de camundongos fêmeas submetidos ao consumo e aplicação tópica de álcool. Resumos do XII Salão e IX Feira de Iniciação Científica da UFRGS; 2000, realizada de 11 a 15 de setembro 2000 em Porto Alegre (RS). Resumos. Porto Alegre: UFRGS; 2000: 325.

48. Martinez M, Martinez FE, Cunha MR, Segatelli TM, Pinheiro PF, Almeida CC. Morphological effects on the hard palatine mucosa of calomys callosys submitted to experimental chronic alcoholism. J Submicrosc Cytol Pathol. 2000;34(1):77-83.

49. Martinez M, Martinez FE, Watanabe I. Morphological changes on the hard palatine mucosa of rats (Rattus Norvegicus Albinus) after chronic alcohol consumption. J Submicrosc Cytol Pathol. 1998;30(3):379-84.

50. Maito FDM, Rados PV, Filho MS, Barbachan, JJ, Quadros $\mathrm{O}$. Proliferating cell nuclear antigen expression on tongue of mice after intake of or topical exposure to alcohol. Alcohol. 2003;31(1-2):25-30.

51. Carrard VC, Filho MS, Rados PV, Chaves AC, Lauxen Ida S. Quantification of silver-staining nucleolar organizer region in epithelial cells of tongue of mice after exposure to, or intake of alcohol. Alcohol. 2004;34(2-3):233-38.

52. Slomiany BL, Piotrowski J, Piotrowski E, Slomiany A. Induction of buccal mucosal apoptosis with chronic alcohol ingestion. Biochem Mol Biol Int. 1998;44(2):381-89.

53. Pöschl G, Seitz HK. Alcohol and cancer. Alcohol Alcohol. 2004;39(3):155-65.

54. Garro AJ, Seitz HK, Lieber CS. Enhacement of dimethylnitrosamine metabolism and activation to a mutagen following chronic ethanol consumption. Cancer Res. 1981;41(1):120-24.

55. Espina N, Lima V, Lieber CS, Garro AJ. In vitro and in vivo inhibitory effect of ethanol and acetaldehyde on O6 metylguanine transferase. Carcinogenesis. 1988;9(5):761-66.

56. Mufti SI, Salvagnini M, Lieber CS, Garro AJ. Chronic ethanol consumption inhibits repair of dimethylnitrosamine-induced DNA alkylation. Biochem Biophys Res Commun. 1988;152(1):423-31.

57. Hsu TC, Furlong C. The role of ethanol in oncogenesis of the upper aerodigestive tract; inhibition of DNA repair. Anticancer Res. 1991;11(6):1995-998.

58. Riveros-Rosas H, Julian-Sanchez A, Piña E. Enzimology of ethanol and acetaldehyde metabolism in mammals. Arch Med Res. 1997;28(4):453-71.

59. Rubin E, Lieber CS. Hepatic microsomal enzimes in man and rat, induction and inhibition by ethanol. Science. 1968;162(854):690-91.

60. Miller JA. Carcinogenesis by chemicals: an overview G.H.A. Clowes Memorial Lecture. Cancer Res. 1970;30(3):559-76.

61. Garro AJ, Espina N, Farinati F, Salvagnini M. The effects of chronic ethanol consumption on carcinogen metabolism and on O6- methylguanine transferase-mediated repair of alkylated DNA. Alcohol Clin Exp Res. 1986;10(6 suppl):73S-77S.

62. Protzel M, Giardina AC, Albino EH. The effect of liverimbalance on the development of oral tumors in mice following the application of benzpyrene or tobacco tar. Oral Surg Oral Med Oral Pathol. 1964;18(5):622-35.

63. Lieber CS. Biochemical and molecular basis of alcoholinduced injury to liver and other tissue. N Engl J Med. 1988;319(25):1639-650.

64. Johnson PJ. Acute and chronic liver disease. In: Marshall WJ, Bangert SK (eds). Clinical biochemistry: metabolic and clinical aspects. New York: Churchill Livingstone; 1995:243-45.

65. Szabo G. Consequences of alcohol consumption on host defence. Alcohol Alcohol. 1999;34(6):830-41.

66. Lundy J, Raaf JH, Deakins S, Wanebo HJ, Jacobs DA, Lee $\mathrm{T}$, et al. The acute and chronic effects of alcohol on the human immune system. Surg Gynecol Obstet. 1975;141(2):212-18.

67. Gallucci RM, Pfister LJ, Meadows GG. Effects of ethanol consumption on enriched natural killer cells from C57B/6 mice. Alcohol Clin Exp Res. 1994;18(3):625-31.

68. Wang HF, Spitzer JJ. Alcohol-induced thymocyte apoptosis is accompanied by impaired mitochondrial function. Alcohol. 1997;14(1):99-105.

69. Deleyiannis FW, Thomas DB, Vaughan TL, Davis S. Alcoholism: independent predictor of survival in patients with head and neck cancer. J Natl Cancer Inst. 1996;88(8):542-49.

70. Seitz HK, Simanowsi UA. Alcohol and carcinogenesis. Annu Rev Nutr. 1988;8:99-119.

71. Maio R, Dichi JB, Burini RC. Implicações do alcoolismo e da doença hepática crônica sobre o metabolismo de micronutrientes. Arq Gastroenterol. 2000;37(2):120-24.

72. Baraona E, Pirola RC, Lieber CS. Acute and chronic effects of ethanol on intestinal lipid metabolism. Biochim Biophys Acta. 1975;388(1):19-28.

73. Zucoloto S, Rossi MA. Effect of chronic ethanol consumption on mucosal morphology and mitotic index in the rat small intestine. Digestión. 1979;19(5):277-83.

74. Simanowski UA, Seitz HK, Baier B, Kommerell B, ShmidtGayk H, Wright NA. Chronic ethanol consumption selectively stimulates rectal cell proliferation in the rat. Gut. 1986;27(3):278-82.

75. Tarnawski A, Lu SY, Stachura J, Sarfeh IJ. Adaptation of gastric mucosa to chronic alcohol administration is associated with increased mucosal expression of growth factors and their receptor. Scand J Gastroenterol. 1990;193(27):59-63.

76. Leo MA, Lieber CS. Alcohol, vitamin A, and beta-carotene: adverse interactions, including hepatotoxicity and carcinogenicity. Am J Clin Nutr. 1999;69(6):1071-1085. 
77. Brunt PW, O'Donnell McGhee J. Chronic alcohol abuse: other systems. Medicine. 1995;23:66-68.

78. Figuero Ruiz E, Carretero Pelaez MA, Cerero Lapiedra R, Esparza Gomez G, Moreno Lopez LA. Effects of the consumption of alcohol in the oral cavity: relationship with oral cancer. Med Oral. 2004;9(1):14-23.

79. Seitz H, Matsuzaki S, Yokoyama A, Omán N, Vakevanen S, Wang XD. Alcohol and cancer. Alcohol Clin Exp Res. 2001;25(5):137-43.

80. Contreras EG. Retinoides: su aplicación en las lesiones precancerosas y el cáncer oral. Med Oral. 2001;6:114-23.

81. Mak KM, Leo MA, Lieber CS. Effect of ethanol and vitamin A deficiency on epithelial cell proliferation and structure in the rat esophagus. Gastroenterology. 1987;93(2):362-70.

82. Rennie JS, McDonald DG, Dagg JH. Quantitative analysis of human buccal epithelium in iron deficiency anaemia. J Oral Pathol. 1982;11(1):39-46.

83. Scott J, Valentine JA, St Hill CA, West CR. Morphometric analysis of atrophic changes in human lingual epithelium in iron deficiency anaemia. J Clin Pathol. 1985;38(9):1025-1029.

84. Navasumrit P, Ward TH, Dodd NJ, O'Connor PJ. Ethanolinduced free radicals and hepatic DNA strand breaks are prevented in vivo by antioxidants: effects of acute and chronic ethanol exposure. Carcinogenesis. 2000;21(1):93-99.

85. Nieto N, Friedman SL, Cederbaum AI. Stimulation and proliferation of primary rat hepatic stellate cells by cytochrome P450 2E1-derived reactive oxygen species. Hepatology. 2002;35(1):62-73.

86. McDonough KH. Antioxidant nutrients and alcohol. Toxicology. 2003;189(1-2):89-97.

87. Wu D, Cederbaum AI. Alcohol, oxidative stress, and free radical damage. Alcohol Res Health. 2003;27(4):277-84.

88. Thomson AD. Alcohol and nutrition. Clin Endrocrinol Metab. 1978;7(2):405-28.

89. Polavarapu R, Spitz DR, Sim JE, Follansbee MH, Oberley
LW, Rahemtulla A, et al. Increased lipid peroxidation and impaired antioxidant enzyme function is associated with pathological liver injury in experimental alcoholic liver disease in rats fed diets high in corn oil and fish oil. Hepatology. 1998;27(5):1317-323.

90. Zhou Z, San X, Kang YJ. Metallothionein protection against alcoholic liver injury through inhibition of oxidative stress. Exp Biol Med. 2002;227(3):214-22.

91. Vincon P, Wunderer J, Simanowsi UA, Koll M, Preedy VR, Peters TJ, et al. Inhibition of alcohol-associated colonic hyperregeneration by ?-tocoferol in the rat. Alcohol Clin Exp Res. 2003;27(1):100-106.

92. Schwartz J, Baker V, Larios E, Desai D, Amin S. Inhibition of experimental tobacco carcinogen induced head and neck carcinogenesis. Oral Oncol. 2004;40(6):611-23.

93. Borsanyi S, Blanchard C. Asymptomatic enlargement of the parotid glands in alcoholic cirrhosis. Southern Med J. 1961;54:678.

94. Mandel L, Baurmash H. Parotid enlargement due to alcoholism. J Am Dent Assoc. 1971;82(2):369-73.

95. Maier H, Born I, Veith S, Adler D, Seitz HK. The effect of chronic ethanol consumption on salivary gland morphology and function in the rat. Alcohol Clin Exp Res. 1986;10(4):425-27.

96. Enberg N, Alho H, Loimaranta V, Lenander-Lumikari M. Saliva flow rate, amylase activity, and protein and electrolyte concentrations in saliva after acute alcohol consumption. Oral Surg Oral Med Oral Pathol Oral Radiol Endod. 2001;92(3):292-98.

97. Wu-Wang CY, Lim C, Slomiany A, Slomiany BL. Impairment by ethanol of prostaglandin production in rat salivary glands. Arch Oral Biol. 1991;36(1):9-13.

98. Mandel ID. The functions of saliva. J Dent Res. 1987;66:623-27.

99. Battino M, Ferreiro MS, Gallardo I, Newman HN, Bullon P. The antioxidant capacity of saliva. J Clin Periodontol. 2002;29(3):189-94.

\section{Abstract}

Alcohol consumption is a risk factor for the development of oral cancer, but the mechanisms involved in the damage caused by alcohol consumption are only partially understood. Certain alcohol levels cause an increase in the permeability of the oral mucosa, facilitating the penetration of carcinogens. Alcohol also increases epithelial proliferation and modifies the epithelial maturation process. Other alterations such as reduced capacity for DNA repair and disorders of the immune system and nutritional status can contribute to the development of oral cancer. Alcohol metabolism increases the production of free radicals and decreases anti-oxidative mechanisms, leading to oxidative stress. Gene polymorphism in the genes involved in alcohol catabolism may account for the difference in individual sensitivity. Some isoforms of these enzymes allow the accumulation of toxic metabolites like acetaldehyde, which damage DNA and other cell structures. Based on a literature review, the current article aims to establish a relationship between the various mechanisms involved in the effect of alcohol and carcinogenesis in the oral cavity.

Key words: Ethanol, Squamous cell carcinoma, Oral mucosa 